\title{
Dynamic and static pricing in open-book accounting
}

Martin Hoshi Larsson and Daniel Ellström

The self-archived postprint version of this journal article is available at Linköping University Institutional Repository (DiVA):

http:// urn.kb.se/ resolve?urn=urn:nbn:se:liu:diva-142295

N.B.: When citing this work, cite the original publication.

Hoshi Larsson, M., Ellström, D., (2017), Dynamic and static pricing in open-book accounting, Qualitative Research in Accounting \& Management/ Emerald, 14(1), 21-37.

https:// doi.org/ 10.1108/QRAM-09-2015-0071

Original publication available at:

https:// doi.org/ 10.1108/ QRAM-09-2015-0071

Copyright: Emerald

http:// www.emeraldinsight.com/ 


\section{Dynamic and Static Pricing in Open-Book Accounting}

Purpose: The purpose of this paper is to understand differences between open-book accounting using static prices and open-book accounting using dynamic prices. We identify how these differences influence various aspects of customer-supplier relationships.

Design/methodology/approach: This paper is based on a case study involving a builders' merchant and a wood manufacturer in the UK. The builders' merchant under discussion has recently outsourced part of its production to the aforementioned wood manufacturer by using open-book accounting with dynamic prices. For this case study, we have conducted interviews with multiple people from both parties in the agreement. Additional illustrative cases are provided through a study of other qualitative papers on open-book accounting.

Findings: We find evidence supporting that, when dynamic prices are used in open-book accounting, risk (unpredictability) is shifted from the supplier to the customer. Also, the customer frequently focuses on the supplier's costs, both parties often aim for a long-term relationship, and the customer becomes more dependent on the supplier, causing high interdependence. Furthermore, empirical evidence suggests that the customer finds price less important, and the reallocation of activities between the customer and supplier is easier in open-book accounting setups in which dynamic prices are used.

Originality/value: This paper provides the first study of how differences between dynamic and static prices in open-book accounting influence the customer-supplier relationship. This paper adds to the developing literature on open-book accounting, in particular, as well as to literature on pricing in general.

Keywords: Open-book accounting, interorganisational cost management, pricing 


\section{Introduction}

Open-book accounting (OBA), the practice where internal cost information and other related information is shared with another firm, was established as an opportunity for firms to extend their collaboration to the field of management accounting (Kulmala, 2002, Windolph and Möller, 2012). Sharing management accounting information can lead to positive outcomes for dyads and networks in terms of interorganisational learning (Kulmala, 2002) and the more cost-effective division of tasks (Kajüter and Kulmala, 2005, Cooper and Slagmulder, 2004). Many firms' with high specialization and focus on core competences depend on their business partners (Barringer and Harrison, 2000). However, due to information asymmetry, inefficiencies can appear in interfirm arrangements when customers' limited insights into their suppliers' operations lead to unnecessarily detailed, cost-driving requirements. Hence, it is important for firms engaged in buyer-seller relationships to align their operations. This is the rationale often used to explain and motivate OBA practice (Cooper and Slagmulder, 2004, Windolph and Möller, 2012).

Although researchers have taken an interest in OBA, there is still a need to broaden the understanding of this accounting method (Suomala et al., 2010, Kajüter and Kulmala, 2005). This paper contributes to the understanding of OBA through an investigation of pricing mechanisms used in OBA contracts. When a supplier's cost data is disclosed, the nature of price change negotiations changes. Two fundamentally different ways to negotiate and determine prices in OBA agreements can be distinguished, namely static prices and dynamic prices. In static price deals, cost information is only indirectly used to inform price decisions, and price is negotiated based on expected value as in non-OBA business relationships. In contrast, when a dynamic price is negotiated, cost information is used to establish the price to be paid by the customer. A key difference between these two pricing mechanisms is that, when the costs of the supplier change, the price is automatically adjusted when dynamic prices are used, whereas new negotiations are required if one of the parties is dissatisfied with static prices. In this paper, we investigate the differences between the use of dynamic and static prices in OBA agreements.

Previous literature describes cases of OBA agreements that employed both dynamic prices (e.g. Alenius et al., 2015, Agndal and Nilsson, 2010, Kumra et al., 2012, Agndal 
and Nilsson, 2008) and static prices (e.g. Kajüter and Kulmala, 2005, Cooper and Slagmulder, 2004, Agndal and Nilsson, 2010, Kumra et al., 2012). Two of the articles mentioned above include cases of both static and dynamic prices. Several quantitative articles about OBA (e.g. Piontkowski and Hoffjan, 2009, Caglio and Ditillo, 2012, Windolph and Möller, 2012) make no distinction between price mechanisms. Therefore, the results of these articles can be difficult to interpret, as different interview respondent and authors assume different kinds of OBA relationships. Axelsson et al. (2002), in their conceptual article discussing OBA, draw a distinction between a transactional and a relational approach to purchasing, but these approaches are not specifically associated with the different pricing mechanisms available. The inclusion of pricing mechanisms in their analysis could have enabled more distinguished conclusions.

When the supplier is given a fixed margin (enabled by dynamic prices), incentives for cutting costs in the supplier's operations decrease for the supplier and increase for the customer. In contrast to OBA agreements in which static prices are used to pressure suppliers to decrease their costs, dynamic price agreements are often long-term and aim to be mutually beneficial for both parties (cf. Alenius et al., 2015). When the customer allows the supplier to adjust prices according to the supplier's costs, OBA strengthens the offering through improved cooperation rather than through price reductions. The role of trust in OBA agreements also varies depending on the selected pricing mechanism. For example, Suomala et al. (2010) describe how, in a dynamic price OBA agreement, the customer may fear that the supplier will act opportunistically and disclose incorrect costs. If static prices were used instead, disclosing incorrect costs would not benefit the supplier in the same obvious way.

These two different pricing mechanisms change the nature of OBA agreements, and a distinction between the two mechanisms can contribute to a better understanding of OBA. Therefore, the purpose of this paper is to understand differences between OBA agreements with static prices and OBA agreements with dynamic prices.

The remainder of this paper is structured as follows. First, we build on existing literature to describe OBA, particularly the pricing mechanisms used in OBA agreements. Second, we present our method for collecting and analysing the case data. Third, we describe the OBA agreement between the two firms of our case study as well as the firms' 
negotiations leading up to their agreement, with a particular focus on pricing. Fourth, we discuss the differences between static and dynamic pricing in OBA, showing a contrast with the previous literature through our case study. Lastly, we present our conclusions.

\section{Open-Book Accounting}

This paper defines OBA as the practice of one firm sharing internal cost information and other related information with another firm. This information includes, but is not limited to, internal cost levels and/or structures. Our definition conforms in general to other definitions of OBA (e.g. Agndal and Nilsson, 2010, Alenius et al., 2015, Kumra et al., 2012, Suomala et al., 2010, Windolph and Möller, 2012). In addition, our definition stresses the fact that the kind of information shared can vary within different OBA agreements. The shared information can range from cost-related data (e.g. Möller et al., 2011) to prognoses (Mouritsen et al., 2001) and product information (Alenius et al., 2015), depending on the intended outcomes of the shared information.

A frequently cited reason for adopting OBA is cost reduction and interorganisational cost management (IOCM) (e.g. Agndal and Nilsson, 2008, Agndal and Nilsson, 2010, Windolph and Möller, 2012, Cooper and Slagmulder, 2004, Axelsson et al., 2002, Munday, 1992). However, the reasons for adopting OBA are numerous (Suomala et al., 2010, Agndal and Nilsson, 2008), including the following:

- The customer gaining knowledge of the production process (Piontkowski and Hoffjan, 2009, Alenius et al., 2015), the market (Agndal and Nilsson, 2010), and how to formulate needs (Seal et al., 1999, Suomala et al., 2010)

- Price pressuring (Munday, 1992, Axelsson et al., 2002)

- Customer control over supplier information (Alenius et al., 2015, Agndal and Nilsson, 2010, Mouritsen et al., 2001)

- Shifting transaction costs (Möller et al., 2011) and profit margin variance (Kumra et al., 2012) from the customer to the supplier

- Shifting focus from price to process (Alenius et al., 2015)

- Error checking (Agndal and Nilsson, 2008, Agndal and Nilsson, 2010) 
- Stimulating transparency (Mouritsen et al., 2001, Cooper and Slagmulder, 2004), nonopportunistic behaviour (Caglio and Ditillo, 2012), commitment (Piontkowski and Hoffjan, 2009), and trust (Tomkins, 2001, Seal et al., 1999, Dekker, 2003).

Agndal and Nilsson (2008) provide a list of seventeen decision-making processes informed by OBA. Three of these processes, named "final price," "future price reductions," and "price revisions based on changes in conditions," relate to price decisions (Agndal and Nilsson, 2008, p. 162). Discussions on final price may be influenced by the presence of cost data, which may also change perceptions of how pricing should evolve in the future. Moreover, uncertainties related to cost may shape how future price corrections are made.

Additionally, Kumra et al. (2012) and Windolph and Möller (2012) discuss how suppliers can manage their profit margins by opening their books. Cost information typically informs price negotiations and allows for dynamic prices.

However, the articles mentioned in the previous paragraph are exceptions to the norm, as most articles in this area do not discuss the relationship between price decision-making and OBA. Many articles implicitly touch on the topic, providing clues about what price models can be used within OBA (Piontkowski and Hoffjan, 2009, Axelsson et al., 2002, Caglio and Ditillo, 2012), but no extant literature has analyzed how different price models can relate to other aspects of OBA.

\section{Pricing in $O B A$}

The literature on price models in OBA is scarce. Within pricing literature, Iveroth et al. (2013) explicitly underscore some features of price models in their SBIFT model (scope, base, influence, formula, and temporal rights), but their model cannot smoothly accommodate dynamic OBA cases, where prices are ultimately determined after the costs have been realised, as the price formula is both negotiated and result based. Neither does Diamantopoulos's (1991) taxonomy of pricing methods accommodate for such a case. Possibly, these articles manifest the fact that OBA has been poorly investigated from a price model perspective. The claim by Özer \& Phillips (2012) that we need more research answering questions of who, how, and why regarding pricing processes further supports the need for a study like ours. 
As previously mentioned, cost information shared within OBA agreements may inform joint price decisions. Cost information may, for example, partially form the basis of contract negotiations, during which agreed upon prices will be set while keeping costs in mind. If costs are expected to vary over time, the price model may be designed to accommodate for varying costs. Such a design may be used if production efficiency is expected to increase over time, thus lowering costs. Prices in this case could be set to decrease by a certain percentage each year.

The joint realization that costs may vary depending on unforeseeable conditions may also lead parties to include in their agreement the intent of renegotiating price levels at a later stage if conditions change. Such condition-contingent renegotiations may be triggered by conditions that are implicit (e.g. "if competition increases”) or explicit (e.g. “if steel prices drop by more than 5 percent”). Furthermore, subsequent negotiations could also be substituted for a predefined set of rules or algorithms which, given some input, produces a set of contract conditions (e.g. a product highly dependent on steel prices could be priced dynamically depending on current steel prices, to avoid renegotiations). Iveroth et al. (2013) refer to prices as exogenous when they are contingent on factors beyond the influence of both the supplier and customer. In Iveroth et al.'s dynamic, but closed book example, prices were based on an index calculated from the cost of oil, wages, and GDP growth. In contrast, costs are not strictly exogenous in this sense, as they can be directly affected by the parties. When price models in contracts are based on costs shared within an OBA agreement, these dynamic cost-based prices give rise to a number of important aspects that are tightly related to OBA, which we will discuss below.

Price levels are normally agreed upon as part of a contract between parties. Costs may be considered (and indeed will be when OBA is applied) by one or both parties during contract negotiations, and these prices often take the form of static statements to be followed when the time of payment comes. In this paper, we refer to such a practice as using static prices. The alternative to this kind of pricing is using dynamic prices, which are price levels contingent on conditions observed after the contract agreement. A subset of dynamic prices is when OBA allows prices to be dynamic according to a posteriori measured costs. This paper deals exclusively with cost-based prices, and "static prices" and “dynamic prices” will refer only to cost-based prices (the lower row in Table 1). 
Price flexibility

\begin{tabular}{|c|c|c|c|}
\hline & & \\
\hline & & Static & Dynamic \\
\hline \multirow{3}{*}{ Cost Consideration } & No Consideration & $\begin{array}{c}\text { Market- and Value- } \\
\text { Based Prices }\end{array}$ & Exogenous Prices \\
\hline & Open-Book & Static Cost-Based & Dynamic Cost- \\
\hline & Agreement & Prices & Based Prices \\
\hline
\end{tabular}

OBA allows for costs to be included in the determination of prices. When static prices are used, previous costs serve to estimate future costs. These cost estimates then serve as input for estimations of margins or similar key performance indicators, which in turn serve as input for price determination. When dynamic prices are used, actual costs can instead be used in these calculations. Theoretically, this practice allows for guarantees of margin levels, so long as the ways to specify how cost will be calculated are correct and mutually agreed upon, and the agreement is honoured. In practice, it may be difficult to correctly calculate costs, but, as long as the calculations are sufficiently accurate, margins will be close to what they were intended to be.

Points of relevance to consider in dynamic pricing

Dynamic prices can be determined in a number of ways. The simplest case is when price, $\mathrm{P}$, is determined as a function of a range of observed costs, $\bar{C}$ :

$$
P=f(\bar{C})
$$

Agndal and Nilsson (2008) give an example of this type of pricing being used, presenting a case in which a car manufacturer allowed a car parts supplier to adjust prices according to changes in costs associated with the sourcing of materials.

These price functions can also be based on calculations of margins or other types of performance figures. In this case, dynamic prices allow the supplier fixed margins. Not only costs but also other types of information serve as input for price calculation. For example, net profit margin is normally calculated as such:

$$
\text { net profit margin }=\frac{\text { net profit }}{\text { revenue }}=\frac{\text { revenue }- \text { costs }}{\text { revenue }}
$$


Revenue is directly related to prices and quantities. Consequently, if the parties have agreed on a fixed net profit margin for the supplier, they base the price calculation on information about costs, $\bar{C}$, as well as quantity, $Q$ :

$$
P=f(\bar{C}, Q)
$$

As prices symbolize the amount of money to be transferred from one party to the other, payments are related to cost calculations when prices are based on such calculations. Payments can potentially occur as soon as the contract has been signed, but payments scheduled before the calculation of actual costs will have to be template payments, which are later supplemented with adjustment payments to accommodate for true cost levels. This is, for example, seen in a case given by Alenius et al. (2015) in which "Positive differences result in profit sharing with [the customer] and negative differences in compensation from [the customer]” (p. 200). Naturally, payments are scheduled after cost calculations, but estimations of payment amounts will nevertheless require estimations of costs, calculated in the same way as the final costs. In other words, the books may need to be opened at multiple points in time to allow price adjustments and corresponding payments.

In addition to net profit margin, examples of other extremely common key performance indicators include earnings before interest and tax (EBIT) and return on capital employed (ROCE):

$$
E B I T=\text { earnings before interest and taxes }=\text { revenue }- \text { costs }+ \text { interest and taxes }
$$

$$
R O C E=\frac{E B I T}{\text { capital employed }}
$$

For all such key performance indicators when dynamic prices are used, a common procedure is when revenues (and consequently prices) are solved for and then determined by the input of cost and previously decided margin levels. Advanced measures of margins, such as ROCE, also include other key figures, such as capital employed. Such figures also need to be provided by the supplier through the use of OBA, and the customer has to trust the figures. Furthermore, the customer must also trust the supplier not to adjust the figures (e.g. employ more capital) in order to increase price levels. This is in contrast to the how the supplier has to trust the customer to not abuse shared data within OBA (e.g. Kajüter and Kulmala, 2005). 
In summary, dynamic cost-based prices require OBA, and OBA can happen for a number of reasons, one of them being the use of dynamic prices. Depending on what type of key performance indicator is used as a basis for the prices, different kinds of cost information need to be shared.

Differences between dynamic and static prices in $O B A$

When a predetermined margin is used with OBA, risk associated with costs will shift from the supplier to the customer. The customer's willingness to accept this risk increase results either from the customer occupying in a low power position, thus allowing the supplier to demand the risk increase (see Crook and Combs, 2007, Ramsay, 1994), or from the customer's anticipation of benefits that outweigh the increased risk, such as a better understanding of cost efficiency. This effect is expressed in the following proposition.

- $\quad$ Proposition 1: The customer takes more risk when dynamic prices are used.

In addition to the transfer of risk, the incentive to reduce the supplier's costs will be shifted from the supplier to the customer. By lowering the supplier's costs, prices to be paid by the customer decrease. The cost transparency associated with OBA allows the customer to get insights regarding how the supplier's costs are driven, and how they affect the customer's operations. Hence, a customer in a dynamic price setting could use this information to define the parameters on which the price calculation is based. For example, the customer could offer to rent a factory to the supplier, lowering the capital employed by the supplier and by extension lowering the price level required to reach the agreed upon ROCE. Similarly, the customer could benefit from suggestions that decrease the supplier's costs, as these suggestions lower purchasing prices for the customer. This effect is expressed in the following proposition.

- Proposition 2: The customer is more focused on supplier costs when dynamic prices are used. 
To set up a deal in which dynamic prices are used, the two companies must agree on a fair return that the supplier is entitled to. In addition, they also have to negotiate how this return should be calculated. We suggest that dynamic prices lead to contracts being renegotiated less frequently, thus increasing stability. Setting up a contract like this requires the two firms have a long-term focus in their engagement with the dynamic price contract and their relationship. We accordingly make the following proposition.

- Proposition 3: A long-term focus in business relationships is more common when dynamic prices are used.

Given that dynamic pricing is associated with a long-term focus and the customer's increased attention on supplier costs, the customer is more prone to invest in the supplier's operations. Cost-cutting investments require the customer's intent to remain in the business relationship. To achieve a sufficient payoff from the investment, the customer is encouraged to stay with the supplier and reap the benefits of the investment. Thus, investments create an additional lock-in for the customer and the customer's dependence on the supplier to provide cost-efficient operations. This effect is expressed in the following proposition.

- Proposition 4: Customers are more dependent on suppliers when dynamic prices are used, causing high interdependence.

These four propositions concern the consequences of customer-supplier relationships when OBA with dynamic, rather than static, pricing is used. Although these propositions and the theoretical arguments supporting them are interconnected, we examine the propositions separately in the discussion section.

\section{Research Method}

This paper is based on a conceptual discussion of dynamic pricing in OBA, which is then exemplified by a case study. It is valuable to support conceptual arguments with case data (Kindström and Kowalkowski, 2009). These benefits are further described in 
Siggelkow (2007). In addition to the case study carried out as part of this research, empirical descriptions of other case studies of OBA are used to illustrate the differences between static and dynamic pricing. A case study facilitates the opportunity to provide a new theory, which can be used to fuel subsequent deductive approaches (Eisenhart and Graebner, 2007), especially when the studied phenomenon is rare and well delimited in time, and when the studied phenomenon is complex (Dubois and Gadde, 2002). The case study method can provide a deep and nuanced understanding of dynamic price OBA agreements, which in turn allows for the exemplification and early testing of this paper's proposals. As static prices are perceived as the "normal” way to conduct business, we have chosen to study a dynamic price case.

The firms included in the case study are a wood manufacturer and its customer, which is one of the larger builders' merchant chains in the UK. The firms have recently initiated a dynamic price OBA and correspond well to the setting that we aim to study. Therefore, this case is suitable for providing a nuanced picture of the phenomenon under study and thus was sampled theoretically (cf. Eisenhart and Graebner, 2007). Additionally, the openness regarding the information and healthy relationship between the supplier and customer provided an opportunity to study and acquire information from both sides of the agreement. Both firms expressed willingness to gain a deeper understanding of how they can improve their OBA agreement, which further improved our access to information.

This study forms a part of a larger research project in which the supplier and some of its customers have been involved for four years. In total, we conducted more than thirty interviews with managers at different levels in the two firms involved in the case. Because of this, we gained an understanding of the case firms' businesses and the industries in which they operate. This enabled us to focus the data collection for this paper on issues directly related to dynamic prices in OBA. Also, we conducted two unstructured telephone interviews with the commercial director of the supplier. The aim of these interviews was to establish an understanding of how the OBA agreement came to be and to outline the different steps that were taken until the OBA agreement was up and running. Using the two initial interviews and a literature review of OBA as a basis, we formulated an interview guide. We then used this interview guide in four in-depth, on-site interviews in the UK. We interviewed two persons from the supplier side (the commercial director 
and the key account manager) and two persons from the customer side (the head of supply centers and the category director) for approximately two hours each. We chose the respondents in consultation with our contact person from the supplier to make sure the selected respondents were all knowledgeable in the topic. The contact person had no stakes in the research results and we therefore considered the risk for any result-affecting bias in the selection recommendation to be low. We also ensured that the respondents were heterogeneous so as to illuminate the topic from different perspectives. The commercial director of the supplier and the category director of the builders' merchant have more strategic roles in the relationship, whereas the key account manager of the supplier and the head of supply centers of the customer are more involved in the daily operations of the relationship. By involving informants from each side of the OBA agreement with different roles in the business relationship, we have mitigated some of the risk of bias (Eisenhart and Graebner, 2007).

The interviews were recorded and later transcribed. Data was used to illustrate and inform the discussion on dynamic prices in OBA agreements. Although we cannot generalize from case studies (Meyer, 2001, Yin, 2009), this case provides indications that can be tested by future research.

To arrive at our results, we applied a method inspired by grounded theory (Corbin and Strauss, 2008) and systematic combining (Dubois and Gadde, 2002). The first interview guide was grounded in theory, but more theory was also added as results suggested new approaches to understanding the phenomena of OBA and dynamic pricing. Thus, the interview guide was revised throughout the duration of the interview process, meaning answers in early interviews influenced questions in later interviews. More theory was gradually added to understand and refine the vocabulary used to describe the topics emerging from coding of the interview results.

To analyse the data, the recordings of the interviews were revisited multiple times and we structured parts of the answers into emerging topics. One of these topics was pricing, which we later decided to be superordinate to the other topics and we chose it to form the main theme of the study. The following section, in which the case is presented, is divided into a general subsection (in which other emerging topics have been merged) and a second 
specific subsection about pricing. The general subsection has been structured chronologically and also according to the different topics within it.

To compensate for the potential weak generalization of results due to this method, we exemplify our emerging propositions with secondary data from other studies on OBA. In other words our method is theory generation, grounded in the study of a rare but important phenomenon.

\section{The Development of Open-Book Accounting with Dynamic Prices in the WoodCutter Scenario}

The timber supplier and wood manufacturer studied in this case is henceforth referred to as WoodCutter, and its customer in the builders' merchant sector will be referred to as Merchant. In this study, the investigated product category includes machined wood, sheet material, and plywood. WoodCutter also distributes wood products to a sister firm of Merchant, SisterChain.

In 2010, in the wake of the Great Recession, WoodCutter lost customers and had to face the challenge of either finding new customers or shutting down parts of its business. At the same time, Merchant was looking into outsourcing their machining of softwood and was looking for alternative investment opportunities. Merchant had little knowledge regarding the efficiency of its machining operations, and outsourcing therefore provided the potential to reduce costs. In addition, Merchant assumed the security of supply would increase if the machining was carried out by a timber supplier that had internal access to the raw material used. At this point in time, the communication level between Merchant and WoodCutter was low, albeit friendly. Representatives from the firms met and discussed possibilities for joint efforts, and this meeting resulted in a small project ending in a test offer by WoodCutter in 2011. Merchant made no reply, and the efforts froze.

At a coincidental meeting in 2012 between the chairman of Merchant's parent company and the managing director of WoodCutter, it was agreed that WoodCutter would again provide a quote for replacing part of Merchant's manufacturing. Merchant also looked at other potential suppliers but discarded these alternatives due to past relational problems. 
The project of providing a quote on the joint venture that showed the venture's costsaving potential lasted until 2012, and the conclusion drawn by Merchant's parent company was that the potential savings were not low enough to warrant the risk associated with a presumably complex business relationship. However, Merchant's parent company identified an opportunity for a bigger effort, in which WoodCutter would supply wood products not only to Merchant but also to SisterChain. WoodCutter was asked to provide a quote with full cost information disclosure in order for Merchant to compare the quote with its internal costs. The cost comparison provided insight into the relative efficiency of Merchant's machining operations, something that was difficult to obtain otherwise. This was critical to Merchant's decision to outsource, as it also considered keeping production in-house. After receiving the quote, Merchant's parent company concluded that the savings would be sufficiently large, as outsourcing would reduce the costs of wood distribution by approximately 10 percent. The supply to both Merchant and SisterChain were awarded to WoodCutter at the end of 2012 and the beginning of 2013.

One of the main reasons Merchant awarded the order to WoodCutter was the higher security of supply. The timber category director of Merchant expresses that "[WoodCutter] has a supply of raw material. Forestry ownership is high, which gives us comfort in that they have the resources we need to move forward. The choice is a risk lowerer for [Merchant].” WoodCutter's forestry ownership decreases the risk of shortages, which would affect Merchant.

Deliveries to SisterChain started in July 2013 and were at first plagued by major performance issues at WoodCutter's site. WoodCutter had not planned correctly, and, adding to this, SisterChain's demand had built up as a result of its previous supplier withholding deliveries for the last three weeks of their contract, which SisterChain failed to report to WoodCutter. SisterChain chose to support WoodCutter through the rough patch by sending consultants, but it also fined WoodCutter, leading to disastrous economic results for WoodCutter in 2013. After a few months, delivery performance became satisfactory according to all parties. The relationship between SisterChain and WoodCutter has been continuously good on the commercial side, despite delivery performance issues from time to time. 
Merchant decided to initiate the OBA agreement with the intent of increasing cost efficiency and thereby competitiveness. As WoodCutter was able to show that it could reduce Merchant's current manufacturing costs, Merchant decided to go along with the deal. With their current OBA agreement, a better understanding of costs creates confidence in that Merchant remains competitive in the marketplace, according to the head of supply centers at Merchant. As the OBA decision was made as part of the decision to outsource Merchant's wood product manufacturing, it also reduced Merchant's capital tied up in machining facilities.

The key account manager at WoodCutter considers the knowledge transfer in the OBA agreement to be more important than the cost cuts. According to WoodCutter's account manager, the two companies work closer together than what is conventional, and knowledge is transferred both ways. The category director of Merchant also suggests that there is knowledge transfer between the companies, claiming that "we needed someone who knows timber and machinery, so we see them as good support . . . we need their expertise behind the scenes.” Similarly, Merchant provided support to WoodCutter in the form of a project manager who looked after the transition at WoodCutter's production site.

Through the OBA agreement, WoodCutter gets to know the customers’ needs better, and Merchant gets insight into manufacturing cost drivers.

WoodCutter's account manager perceives the deal to provide safety and security of supply and demand for both parties. The head of supply centers at Merchant similarly thinks that the purpose of OBA was to "get a long-term view of what was happening” and “tie in” both parties. WoodCutter is guaranteed a large consistent sales volume over time with a fixed return (hence a dynamic price), and Merchant becomes a preferred customer with good insight into WoodCutter's operations. Merchant would be quickly notified if there were shortages of material or if other important changes took place in WoodCutter's operations.

Previous literature raises trust as a possible incentive to use OBA, but this is not explicitly found in this case. The head of supply centers at Merchant claims that OBA should breed better trust but does not consider it as a reason why OBA is used in this specific case. 
While WoodCutter made the suggestion to outsource Merchant's wood manufacturing, the initiative to use OBA clearly came from Merchant. This kind of setup had been used by Merchant with other suppliers, and, as mentioned above, Merchant wanted to ensure high cost efficiency in their operations.

Even though WoodCutter had no previous experience with opening its books, it did not clearly oppose the OBA agreement. The deal was strategically important for WoodCutter, as it meant that the company would increase its sales volumes substantially. Merchant also made it clear from the beginning that OBA was a necessity should the deal happen. Together, this made it easier for WoodCutter to accept the demands placed on it regarding the deal, and the choice to use OBA was never questioned. The key account manager of WoodCutter also perceives the deal to be fair, as long as both parties are honest.

The OBA agreement between WoodCutter and Merchant as well as between WoodCutter and SisterChain has been formalized in contracts lasting until 2018, with a one-year advance termination notice clause. According to WoodCutter, the contract is needed both as a reference to claim what is expected from the other party and as a steering document. The contract includes a fund to cover the merchandising team's costs and another fund to cover marketing. WoodCutter demanded that such funds be part of the contract. The explicitness of the contract has turned out to be an asset when explaining the rules of collaboration to noninitiated people. Regardless, Merchant states that no matter how good the contract is, trust is always needed to have a close collaboration like theirs work.

In the data collection, there are indications of both high and low trust between the parties. The head of supply centers at Merchant expresses that the two parties had a sporadic relationship before the discussions about the deal were initiated. There were some problems before and during the first weeks of delivery that caused annoyance and frustration on Merchant's part. However, Merchant believes that the problems were related to the launch and that they will not be repeated. Now that the deal is signed, respondents indicate that there is some degree of trust in the relationship. The commercial director of WoodCutter trusts Merchant not to change its wood supplier abruptly, even after the contract expires, and the head of supply centers at Merchant claims that people 
do not distrust each other in their business relationship. The key account manager of WoodCutter thinks that trust is built between the parties through openness and honesty. When the OBA agreement was rolled out, the head of supply centers at Merchant saw no reason to stop using open books and claims that OBA should breed better trust between the parties.

\section{Pricing}

The deal between Merchant and WoodCutter is based on a dynamic price contract. Specifically, the contract states that WoodCutter is guaranteed a return on capital employed. Both parties believe that it was easy to agree upon how much return on capital employed WoodCutter would get, as WoodCutter's expectations were on par with Merchant's internal goal. This made both parties perceive the suggested number as fair. Because WoodCutter has a newly established mill that is solely devoted to manufacturing products for Merchant, it is possible to acquire a good understanding of how much capital the manufacturing for Merchant employs.

During the OBA implementation process, WoodCutter miscalculated and underestimated some of the costs incurred in the production and distribution of Merchant's products. After the contract was signed, and the deliveries to Merchant had begun, WoodCutter became aware of such miscalculations. WoodCutter then had to increase its prices to maintain the agreed upon margin. This was a source of conflict, as Merchant from that point on had to pay more for the products due to mistakes made by WoodCutter. Revisiting the contract to renegotiate these inaccuracies was not an option for either party, as it could potentially bring many other topics up for renegotiation. The increased costs were relatively small, but if the miscalculations were larger in magnitude, they could have posed the risk of the agreement breaking down.

\section{Discussion}

Several articles about OBA are qualitative and provide fairly rich case descriptions of interorganisational relationships in which OBA has been applied. For this discussion, we have selected six articles that provide descriptions of thirteen cases in which OBA was used. We chose articles based on the richness of information in the cases in order to 
illustrate the diversity of pricing mechanisms used in OBA. Based on the descriptions, it is possible to distinguish which relationships employed dynamic prices and which relationships used static prices, with the exception of one case. Of the cases where the pricing mechanism could be determined, dynamic pricing was used in six of the cases, static pricing was used in five cases, and one case included both static and dynamic prices. The mixed pricing case involves relationships between a customer firm, EuroCar, and several of its suppliers. EuroCar had different contracts with different suppliers and used both dynamic and static prices. Table 2 accounts for the various OBA cases described in the previous literature and the pricing mechanisms used in each case. 
Table 2: Pricing mechanisms used in previously described OBA cases.

\begin{tabular}{|c|c|c|c|}
\hline Author & Case & $\begin{array}{l}\text { Pricing } \\
\text { mechanism }\end{array}$ & $\begin{array}{l}\text { Indication of pricing } \\
\text { mechanism in text }\end{array}$ \\
\hline \multirow[t]{3}{*}{$\begin{array}{l}\text { Agndal and Nilsson } \\
\text { (2010) }\end{array}$} & VehicleMaker & Dynamic & $\begin{array}{l}\text { Profit sharing model supported } \\
\text { by disclosed cost data }\end{array}$ \\
\hline & ReTailer & Dynamic & $\begin{array}{l}\text { Profit sharing model supported } \\
\text { by disclosed cost data }\end{array}$ \\
\hline & TeleCom & Static & $\begin{array}{l}\text { Disclosed cost data used for } \\
\text { price negotiations }\end{array}$ \\
\hline Alenius et al. (2015) & $\begin{array}{l}\text { Food Store and } \\
\text { Meat Pack }\end{array}$ & Dynamic & $\begin{array}{l}\text { Meat Pack updates the open } \\
\text { calculation with actual outcome } \\
\text { numbers . . . Positive differences } \\
\text { result in profit sharing with the } \\
\text { food store, and negative } \\
\text { differences result in } \\
\text { compensation from the food } \\
\text { store }\end{array}$ \\
\hline \multirow[t]{3}{*}{$\begin{array}{l}\text { Cooper and Slagmulder } \\
\text { (2004) }\end{array}$} & Komatsu and Toyo & Static & $\begin{array}{l}\text { Komatsu uses target costing } \\
\text { methodology }\end{array}$ \\
\hline & Isuzu and JKC & Unknown & No indication provided \\
\hline & $\begin{array}{l}\text { Tokyo, Yokohama } \\
\text { and Kamakura }\end{array}$ & Static & $\begin{array}{l}\text { Tokyo Motors uses target } \\
\text { costing methodology }\end{array}$ \\
\hline $\begin{array}{l}\text { Kajüter and Kulmala } \\
\text { (2005) }\end{array}$ & Eurocar & Mixed & $\begin{array}{l}\text { A variety of agreements have } \\
\text { emerged. These include, for } \\
\text { example, the equal sharing of } \\
\text { benefits, the allocation of } \\
\text { benefits only to the supplier, } \\
\text { which in turn promises not to } \\
\text { increase the price, or the } \\
\text { allocation of benefits only to the } \\
\text { customer. }\end{array}$ \\
\hline $\begin{array}{l}\text { Kajüter and Kulmala } \\
\text { (2005) }\end{array}$ & $\begin{array}{l}\text { Finnish } \\
\text { Manufacturing }\end{array}$ & Static & $\begin{array}{l}\text { Cost-reduction objectives } \\
\text { "Benefit sharing was not based } \\
\text { on a systematic procedure but } \\
\text { rather on contingency" }\end{array}$ \\
\hline \multirow[t]{3}{*}{ Kumra et al. (2012) } & Yantra Tractor & Dynamic & Guaranteed profit margins \\
\hline & $\begin{array}{l}\text { Nirmaan } \\
\text { Construction } \\
\end{array}$ & Dynamic & Guaranteed margins \\
\hline & Vigyaan IT & Static & $\begin{array}{l}\text { OBA mainly used for price } \\
\text { negotiations }\end{array}$ \\
\hline Agndal \& Nilsson (2008) & CarMaker & Dynamic & $\begin{array}{l}\text { Profit margin of the supplier } \\
\text { was determined jointly }\end{array}$ \\
\hline
\end{tabular}

Our case study, complemented by descriptions in previous case studies, supports the four previously presented theoretical propositions. This is further explained below.

Proposition 1: The customer takes more risk when dynamic prices are used

In the WoodCutter case, the supplier receives a predetermined margin. The supplier perceives the financial risk as relatively small, as it is guaranteed to make a profit from the relationship. As the risk for Woodcutter is low, the risk for the customer (Merchant) 
is consequently higher. Merchant had previously been responsible for manufacturing, and the OBA agreement is part of an outsourcing decision. Merchant was likely more acceptant towards high risk, as they were used to assuming full responsibility for the manufacturing. With dynamic, rather than static pricing, the risk for Merchant is higher, which indicates support for proposition 1.

In the static price case of Komatsu and Toyo (Cooper and Slagmulder, 2004), the suppliers' engineers had to find ways to alter the customer's specifications when the estimated costs of production exceeded the target costs. In this case, the supplier took on risk and was consequently responsible for keeping costs down.

Proposition 2: The customer is more focused on supplier costs when dynamic prices are used

With dynamic prices, the customer is rewarded with decreased prices when the costs of the supplier decrease. For this reason, several of the dynamic price cases show customers supporting their suppliers' operations and trying to find ways of achieving cost reductions.

As for the WoodCutter case, costs were the initial focus of Merchant when it asked WoodCutter to open its books. Previous costs were used as estimates of future costs, and the conclusion was that outsourcing to WoodCutter would be more cost-efficient than keeping the production in-house. Since dynamic prices are used in the agreement, Merchant repeatedly monitors how WoodCutter's costs affect prices. At a later stage, Merchant further intends to provide WoodCutter with information which may lead to a decrease of costs for WoodCutter. Proposition 2 is thus supported by the case at hand.

The case of Food Store and Meat Pack provides an example of the customer supporting the supplier in reducing costs. Alenius et al. (2015) describe that "to lower meat-packing cost both Meat Pack and Food Store has [sic] worked to improve processes in the [supplier’s] factory” (Alenius et al., 2015, p. 199). In the dynamic price cases described by Kumra et al. (2012), the customers provided feedback on suggested efficiency improvements or cost reductions. In the CarMaker case, the customer contributed to the identification of potential cost reductions for the supplier in the product development stage (Agndal and Nilsson, 2008). During full-speed production, the customer sent a "supplier development team" to the supplier with the aim to improve efficiency in the supplier’s operations. Nirmaan Construction used dynamic margins but only provided 
sporadic feedback to suppliers regarding ways to reduce costs (Kumra et al., 2012). This was, however, not because of lack of interest but rather because Nirmaan Construction lacked the expertise required. The customer instead initiated joint value chain analyses with the aim to reduce costs (Kumra et al., 2012).

When static prices are used, the customer does not automatically benefit from cost reduction, and it can therefore be assumed that customers focus less on the suppliers' costs as compared to when dynamic prices are used. This is seen in the case of Vigyaan IT, a customer that "very rarely [became] involved in a supplier's internal processes” and gave "little or no feedback on the data that suppliers [provided]” (Kumra et al., 2012, p. 204). It is instead the suppliers themselves that are most inclined to reduce their own costs, as they are often played against each other to minimize price levels (Kumra et al., 2012).

Proposition 3: A long-term focus in business relationships is more common when dynamic prices are used

Dynamic prices provide security for the supplier and are associated with interdependent relationships. For these reasons, it can also be argued that OBA based on dynamic prices relies on and fosters long-term relationships. WoodCutter and Merchant express that their dynamic price deal provides safety for both parties and that it is intended to achieve a long-lasting relationship. As the timber category manager of Merchant puts it, "The agreement is a partnership project. It is over five years, which is unusually long for us. We want to make sure we give [WoodCutter] commitment to invest in.” These observations support proposition 3.

In the Yantra Tractor case, the supplier's ability to meet the customer's requirements on a long-term basis was more important than price (Kumra et al., 2012). CarMaker and its suppliers also had a long-standing relationship (Agndal and Nilsson, 2008). In the three other cases described by Agndal and Nilsson (2010), the companies using dynamic price OBA typically had long-term relationships, whereas the company using static prices typically had short-term relationships. The "expressed purchasing strategy [involved] long-term arrangements” (Agndal and Nilsson, 2010, p.155), and the relationships “[spanned] across long periods of time” (Agndal and Nilsson, 2010, p.157) in the dynamic price cases. The relationships were "typically limited in time” (Agndal and Nilsson, 2010, p.157) in the static price case. 
Proposition 4: Customers are more dependent on suppliers when dynamic prices are used, causing high interdependence

Since, in the use of dynamic prices, the prices paid by customers are affected by supplier costs, the customer becomes dependent on the supplier and the efficiency of its operations. In the relationship between Woodcutter and Merchant, mistakes in terms of miscalculated costs by WoodCutter resulted in higher prices for Merchant. With a dynamic pricing mechanism, the customer becomes dependent on the accurate cost calculations of the supplier. If new costs appear or are identified, the prices paid by the supplier automatically increase. These observations indicate support for proposition 4.

VehicleMaker and ReTailer both used dynamic prices, and their relationships with their suppliers were characterized by interdependence, at least in the short term (Agndal and Nilsson, 2008). In the Yantra Tractor case, "the limited number of customers and suppliers often [relied] heavily on each other” (Kumra et al., 2012, p. 203). It can be assumed that the firms were interdependent on each other and that the customer was willing to guarantee a margin for the supplier because the customer was reliant on the supplier's timely deliveries of quality products. In the case of Nirmaan Construction, extreme power asymmetries were common, indicating that the customer's dependence on the supplier was low (Kumra et al., 2012). There is, therefore, no guarantee that interdependence characterizes all relationships in which dynamic prices are used. However, customer dependence on the supplier can be one reason why dynamic (rather than static) prices are used. With an OBA contract based on dynamic prices, the supplier is guaranteed to make a profit, and the customer is guaranteed insight into the supplier's operations.

The static price cases described in previous literature indicate low customer dependence and usually a power imbalance. Kumra et al. (2012) describe the suppliers of Vigyaan IT as having been reluctant to open their books. It can therefore be assumed that there was a power imbalance, as the customer was able to dictate that the suppliers share this information. Agndal \& Nilsson (2010) describe the dependencies in the TeleCom case as normally low. However, the suppliers in the TeleCom case also exhibited discomfort in sharing cost data. The fact that they still accepted this information sharing implies that the suppliers had some dependence on the customer. 
The review of previous case descriptions and the case within this study highlight two additional propositions about the differences between OBA relationships with dynamic prices and static prices. These propositions were not identified in the theoretical argumentation, but arguments supporting them are described below.

The importance of price is lower for the customer when dynamic prices are used

In the dynamic price cases, factors other than price were often important when selecting and evaluating suppliers. Price was not the main criterion for selecting suppliers in the Yantra Tractor case (Kumra et al., 2012), and, in the VehicleMaker case, “suppliers [were] not evaluated primarily on price” (Agndal and Nilsson, 2010, p.155). Attributes other than price were also important for the customer Nirmaan Construction (Kumra et al., 2012).

In the WoodCutter case, prices are important, and one of the initial reasons for outsourcing production to a supplier was to reduce costs. However, the customer's need for technical expertise and security of supply is as important.

In the static price cases, prices seem to be generally more important. For example, the customer Vigyaan IT used OBA primarily to support price decisions (Kumra et al., 2012), and no other factors-such as delivery, precision, or quality-influenced supplier selection.

Another proposition can be induced from these observations:

- Proposition 5: The importance of price is lower for the customer when dynamic prices are used.

The reallocation of activities between the customer and supplier is easier when dynamic prices are used

When prices are automatically adjusted as a consequence of cost changes, changes in who does what do not necessarily lead to renegotiations. If the open books uncover that an activity currently carried out by the supplier could be more efficiently carried out by the customer, the activity could be moved, and thus the costs associated with that activity could be removed from the supplier. Consequently, the price paid by the customer would be automatically adjusted. As no new price negotiation has to be conducted when using dynamic prices, this pricing mechanism simplifies the reallocation of activities between 
the involved actors. Some support for this claim can also be found in previous case descriptions of OBA.

For the Yantra Tractor case, Kumra et al. (2012) describe OBA as an enabler of joint product development, indicating that activities could be shared or relatively easily moved between the companies: "Either Yantra Tractor Ltd makes a unilateral investment in special tools and fixtures particular to the supplier's product or the supplier installs such assets on loan from Yantra Tractor Ltd” (Kumra et al., 2012, p. 201). For CarMaker, the open books data was used to determine which party should carry out certain tasks, such as assembly or quality control (Agndal and Nilsson, 2008).

Agndal and Nilsson (2010) describe the main purpose of cost data disclosure in their two dynamic price cases as "cost efficient products and manufacturing processes for both parties” and as "designing efficient supply chain flows” (p. 158). In the static price case, the main purpose of cost disclosure was instead to achieve price controls. This indicates that when dynamic prices are used, activities are moved between the supplier and the customer depending on where they can be most efficiently carried out.

These examples allow for the induction of another proposition:

- Proposition 6: The reallocation of activities between the customer and supplier is easier when dynamic prices are used.

\section{Conclusions}

In the previous literature on OBA, no clear distinction was made between contracts based on dynamic prices and contracts based on static prices. This paper elaborates on the importance of making this distinction. Six propositions are formulated regarding these differences-four propositions based on a theoretical argumentation supported by empirical evidence (from this study and others), and two additional propositions solely based on empirical evidence. The propositions suggest that, when dynamic prices are used, (1) customers take on more risk; (2) customers are more focused on supplier costs; (3) a long-term focus in the business relationships is more common; (4) customers are more dependent on suppliers, causing high interdependence; (5) the importance of price is 
lower for customers; and (6) the reallocation of activities between customers and suppliers is easier.

Although further validation is required, based on the arguments in this paper, the following points are relevant for academics and practitioners alike when discussing contracts based on OBA with dynamic prices:

- What costs to consider. Cost consideration could range from the consideration of only raw materials to the complete consideration of all transaction costs (see Williamson, 1979).

- How to measure costs. Disregarding this point is possibly a source of conflict in these types of agreements.

- What type of key performance indicators to use, and the determination of a fair level of return.The agreement on compensation to the supplier in dynamic price OBA could be a challenging task.

Future research on OBA needs to consider the distinction between dynamic and static prices. The pricing mechanism used affects other aspects of business relationships and their outcomes. Future research can deepen the understanding of OBA if it specifies which OBA price model is targeted, and findings can be better understood by including the pricing mechanism as an explanatory factor.

Additionally, future studies of OBA should clarify firms' intentions in using OBA. Depending on whether an agreement was initiated by the supplier or the customer and what the motivation for using OBA was, the outcome of the agreement might differ. Previous research has covered both the requirements and consequences of OBA, but it has not investigated if outcomes vary depending on agreements' intended outcomes. It is likely that intentions are an important factor that can help explain the outcomes of OBA agreements.

\section{References}

AGNDAL, H. \& NILSSON, U. 2008. Supply chain decision-making supported by an open books policy. International Journal of Production Economics, 116, 154-167. AGNDAL, H. \& NILSSON, U. 2010. Different open book accounting practices for different purchasing strategies. Management Accounting Research, 21, 147-166. 
ALENIUS, E., LIND, J. \& STRÖMSTEN, T. 2015. The role of open book accounting in a supplier network: Creating and managing interdependencies across company boundaries. Industrial Marketing Management, 45, 195-206.

AXELSSON, B., LAAGE-HELLMAN, J. \& NILSSON, U. 2002. Modern management accounting for modern purchasing. European Journal of Purchasing \& Supply Management, 8, 53-62.

BARRINGER, B. R. \& HARRISON, J. S. 2000. Walking a tightrope: Creating value through interorganizational relationships. Journal of management, 26, 367-403.

CAGLIO, A. \& DITILLO, A. 2012. Opening the black box of management accounting information exchanges in buyer-supplier relationships. Management Accounting Research, 23, 61-78.

COOPER, R. \& SLAGMULDER, R. 2004. Interorganizational cost management and relational context. Accounting, Organizations and Society, 29, 1-26.

CORBIN, J. M. \& STRAUSS, A. L. 2008. Basics of qualitative research: techniques and procedures for developing grounded theory, Sage Publications, Inc.

CROOK, T. R. \& COMBS, J. G. 2007. Sources and consequences of bargaining power in supply chains. Journal of Operations Management, 25, 546-555.

DEKKER, H. C. 2003. Value chain analysis in interfirm relationships: a field study. Management Accounting Research, 14, 1-23.

DIAMANTOPOULOS, A. 1991. Pricing: Theory and Evidence - A Literature Review. In: BAKER, M. J. (ed.) Perspectives on Marketing Management. John Wiley \& Sons Ltd.

DUBOIS, A. \& GADDE, L.-E. 2002. Systematic combining: an abductive approach to case research. Journal of Business Research, 55, 553-560.

EISENHART, K. M. \& GRAEBNER, M. E. 2007. Theory building from cases: Opportunities and challenges. Academy of Management Journal, 50, 25-32.

IVEROTH, E., WESTELIUS, A., PETRI, C.-J., OLVE, N.-G., CÖSTER, M. \& NILSSON, F. 2013. How to differentiate by price: Proposal for a five-dimensional model. European Management Journal, 31, 109-123.

KAJÜTER, P. \& KULMALA, H. I. 2005. Open-book accounting in networks: Potential achievements and reasons for failures. Management Accounting Research, 16, 179-204.

KINDSTRÖM, D. \& KOWALKOWSKI, C. 2009. Development of industrial service offerings: a process framework. Journal of Service Management, 20, 156-172.

KULMALA, H. I. 2002. Open-book accounting in networks. Liiketaloudellinen Aikakauskirja, 157-180.

KUMRA, R., AGNDAL, H. \& NILSSON, U. 2012. Open book practices in buyersupplier relationships in India. Journal of Business \& Industrial Marketing, 27, 196-210.

MEYER, C. B. 2001. A case in case study methodology. Field methods, 13, 329-352.

MOURITSEN, J., HANSEN, A. \& HANSEN, C. Ø. 2001. Inter-organizational controls and organizational competencies: episodes around target cost management/functional analysis and open book accounting. Management Accounting Research, 12, 221-244.

MUNDAY, M. 1992. Accounting cost data disclosure and buyer-supplier partnershipsa research note. Management Accounting Research, 3, 245-250. 
MÖLLER, K., WINDOLPH, M. \& ISBRUCH, F. 2011. The effect of relational factors on open-book accounting and inter-organizational cost management in buyersupplier partnerships. Journal of Purchasing and Supply Management, 17, 121131.

PIONTKOWSKI, J. O. \& HOFFJAN, A. 2009. Less is sometimes more: The role of information quantity and specific assets in the propensity to engage in cost data exchange processes. Journal of Purchasing and Supply Management, 15, 71-78.

RAMSAY, J. 1994. Purchasing power. European Journal of Purchasing and Supply Management, 1, 125-138.

SEAL, W., CULLEN, J., DUNLOP, A., BERRY, T. \& AHMED, M. 1999. Enacting a European supply chain: a case study on the role of management accounting. Management Accounting Research, 10, 303-322.

SIGGELKOW, N. 2007. Persuasion with case studies. Academy of management journal, 50, 20-24.

SUOMALA, P., LAHIKAINEN, T., LYLY-YRJÄNÄINEN, J. \& PARANKO, J. 2010. Open book accounting in practice-exploring the faces of openness. Qualitative Research in Accounting \& Management, 7, 71-96.

TOMKINS, C. 2001. Interdependencies, trust and information in relationships, alliances and networks. Accounting, Organizations and Society, 26, 161-191.

WILLIAMSON, O. E. 1979. Transaction-Cost Economics: The Governance of Contractual Relations. Journal of Law and Economics, 22, 233-261.

WINDOLPH, M. \& MÖLLER, K. 2012. Open-book accounting: Reason for failure of inter-firm cooperation? Management Accounting Research, 23, 47-60.

YIN, R. K. 2009. Case Study Research: Design and Methods, London, Sage Publication.

ÖZER, Ö. A. P., R. 2012. Current challenges and future prospects for pricing management. In: ÖZER, Ö. A. P., R. (ed.) The Oxford Handbook of Pricing Management. OUP Oxford. 